\title{
Environmentally friendly bleaching of cotton using laccases
}

Received: 5 May 2005 / Accepted: 9 August 2005 / Published online: 22 October 2005

(C) Springer-Verlag 2005

\begin{abstract}
A new strain of Trametes hirsuta was found to oxidize various cotton flavonoids. Here we show that laccases of this organism were responsible for oxidation of the flavonoids morin, luteolin, rutin and quercetin. Out of two laccases produced by $T$. hirsuta $(60.7$ and $51.0 \mathrm{kDa})$ the more prominent $60.7 \mathrm{kDa}$ laccase was purified and showed $K_{\mathrm{m}}$ and $k_{\text {cat }}$ values of 75.5, 20.9 and $49.4 \mu \mathrm{M}$ and 72.5, 96.3 and $32.7 \mathrm{~s}^{-1}$, hours on ABTS, syringaldazide and DMP, respectively. Pretreatment of cotton with the $T$. hirsuta laccase resulted in a whiteness increase of $8.5 \%$.
\end{abstract}

Keywords Bleaching of cotton - Trametes hirsuta . Laccase

\section{Introduction}

Enzymes are used for the processing of cotton and many environmentally friendly processes such as bioscouring have been implemented in the industry recently. The advantages are the decrease of water, chemicals, and energy consumption, new possibilities for the reuse of effluents, and milder process conditions. Before finishing of cotton fabrics, noncellulosic constituents which create problems such as poor absorbency and poor re-wetability have to be removed. Some of the conventional pre-treatment steps including desizing, scouring and bleaching consume high amounts of water, generate polluting effluents and can damage fibres. Recently, the potential of enzymes for bioscouring, for re-

\footnotetext{
L. Pereira · G. M. Guebitz $(\bowtie)$

Department of Environmental Biotechnology, Graz University

of Technology,

Petersgasse 12,

8010 Graz, Austria

e-mail: guebitz@tugraz.at

Tel.: +43-316-873-8312

Fax: +43-316-873-8815
}

C. Bastos · T. Tzanov · A. Cavaco-Paulo

Department of Textile Engineering, University of Minho, 4800 Guimarães, Portugal moval of seed coat fragments and for dye decolorisation has been assessed while amylases have been introduced for desizing of starch many years ago (Kandelbauer and Guebitz 2005). Until now, however, no alternatives to chemical bleaching have been proposed.

The purpose of bleaching of cotton is to decolorise natural pigments and to confer a pure white appearance to the fibres. Mainly flavonoids are responsible for the colour of cotton (Hedin et al. 1992; Ardon et al. 1996). The most common industrial bleaching agent hydrogen peroxide is usually applied at alkaline $\mathrm{pH}$ and temperatures close to boiling. However, radical reactions of bleaching agents with the fibre can lead to a decrease in the degree of polymerisation and thus to severe damage. Furthermore, huge amounts of water are needed to remove hydrogen peroxide from fabrics which would cause problems in dyeing. Thus, more specific processes only targeting coloured substances would be advantageous. An enzyme-based system could be integrated in the pectinase-based bioscouring process which has been implemented recently by many companies.

For the bleaching and modification of wood pulp fibres laccase/mediator systems have been successfully used. Based on the observation that fungal laccases can oxidize phenolic moieties of lignin in pulp these enzymes could also decolorize or eliminate coloured flavonoids of cotton attacking phenolic hydroxyl groups.

Laccases (EC 1.10.3.2) are multi-copper-containing enzymes capable of oxidising phenols and aromatic amines, reducing molecular oxygen to water, with the involvement of three types of copper centres with different functions: type 1 (blue copper) catalyses the electron transfer from the substrate while type 2 and type 3 form a three-member cluster that collectively activate molecular oxygen. The range of substrates with which laccases can react is very broad, these enzymes are remarkably nonspecific regarding their reducing substrate. This range can even be widened using mediators such as ABTS (2-2'azino-bis(3-ethylbenz-thiazoline-6-sulfonic acid) and HBT (1-hydroxybenzo-triazole). Many industrial applications of laccases have been described including the decolorisation of textile dyes (Kandelbauer and Guebitz 2005). 
In this paper, we show for the first time that a laccase from a newly isolated strain of T. hirsuta can oxidise flavonoids from cotton resulting in an increase of whiteness.

\section{Experimental}

Organism and culture conditions

Sixteen fungi isolated from nature (forests around Graz, Austria) were incubated on PDA plates containing $1 \mathrm{mM}$ of each flavonoid compound and darkening zones around growing mycelia were monitored visually. The fungi were usually grown on PDA-agar plates for 5 days at $30^{\circ} \mathrm{C}$ and thereafter stored at $4^{\circ} \mathrm{C}$. For enzyme production, $1000 \mathrm{ml}$ Erlenmeyer flasks containing $300 \mathrm{ml}$ of culture medium were used. The growth medium for Trametes sp. contained (per 1 distilled water) $10 \mathrm{~g}$ wheat bran flakes, $1.5 \mathrm{~g}$ yeast extract, $1.0 \mathrm{~g}$ glucose, $0.25 \mathrm{~g} \mathrm{NH}_{4} \mathrm{Cl}, 0.05 \mathrm{~g}$ thiamine dichloride, $0.25 \mathrm{~g} \mathrm{CuSO}_{4}$ and $100 \mathrm{ml}$ salt solution. The salt solution was prepared by dissolving $2 \mathrm{~g} \mathrm{KH}_{2} \mathrm{PO}_{4}, 0.5 \mathrm{~g} \mathrm{MgSO}_{4}$ $7 \mathrm{H}_{2} \mathrm{O}, 0.1 \mathrm{~g} \mathrm{CaCl}_{2} \cdot 2 \mathrm{H}_{2} \mathrm{O}$ and $0.5 \mathrm{~g} \mathrm{KCl}$ in 11 tap water, and $\mathrm{pH}$ adjusted to 5 . Each flask was inoculated using an agar piece $\left(1 \mathrm{~cm}^{2}\right)$ cut from a 5 days old culture growing on PDA-plate. The flasks were incubated at $30^{\circ} \mathrm{C}$ on a rotary shaker (130 rpm). After 3 days, $10 \mu \mathrm{M}$ 2,5-xylidine (final concentration) was added to enhance laccase production. Cultures were harvested by centrifugation at $10,000 \mathrm{rpm}$ for $20 \mathrm{~min}$ and supernatants were stored at $4^{\circ} \mathrm{C}$. Two experiments were conducted in parallel and triplicate samples were analysed. The values in the figures correspond to mean values with a standard deviation lower than $10 \%$.

\section{Oxidation of flavonoids}

Stock solutions of $5 \mathrm{mM}$ of rutin hydrate, morin, flavone, luteolin, apigenin and quercetin (Fig. 1) purchased from Sigma Aldrich were prepared in $4 \% \mathrm{MeOH}$. Oxidation was followed spectroscopically in $1 \mathrm{~cm}$ path length cuvettes by repeated wavelength scans over $15 \mathrm{~min}$. Oxidation was routinely monitored in a final volume of $3 \mathrm{ml}$ with $0.033 \mathrm{mM}$ of the flavonoid compound and $1.5 \mathrm{nkat} \mathrm{ml}^{-1}$ laccase activity in $0.1 \mathrm{M}$ acetate buffer $\mathrm{pH} 5.0$ at $50^{\circ} \mathrm{C}$. The effect of $1 \mathrm{mM}$ of the mediators ABTS and HBT was also studied under the same conditions. The kinetic parameters were determined similarly using different substrate concentrations and $K_{\mathrm{m}}$ and $v_{\max }$ were calculated according to Michaelis-Menten model by non-linear analysis using the program "Origin", version 4.10.

\section{Laccase assays, purification and characterisation}

Laccase activity and protein concentration determination and SDS-PAGE were carried out as described previously (Almansa et al. 2004). Laccase was purified with a strategy modified from Almansa et al. 2004 using fractionated ammonium sulphate precipitation (40 and $85 \%$ ), hydropho-

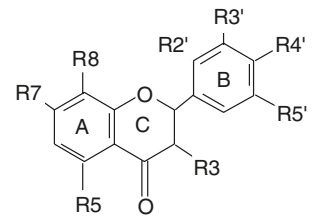

\begin{tabular}{|l|l|l|l|l|l|l|l|l|}
\hline & R3 & R5 & R7 & R8 & R2 & R3' & R4' & R5' \\
\hline Morin & OH & OH & OH & H & OH & H & OH & H \\
\hline Luteolin & H & OH & OH & H & H & H & OH & OH \\
\hline Rutin & Ogl & OH & OH & H & H & OH & OH & H \\
\hline Quercetin & OH & OH & OH & H & H & OH & OH & H \\
\hline Apigenin & H & OH & OH & H & H & H & OH & H \\
\hline Flavone & H & H & H & H & H & H & H & H \\
\hline
\end{tabular}

gl, glycosyl

Fig. 1 Flavone skeleton and substitution pattern

bic interaction chromatography (Phenyl Sepharose CL-4B; $10 \mathrm{mM}$ sodium-acetate $\mathrm{pH}$ 5.0, elution with 1-0 M ammonium sulphate) and 2-step ion exchange chromatography (1. Whatman DEAE cellulose; $10 \mathrm{mM}$ sodium acetate $\mathrm{pH}$ 5.0; elution with 0-1 M NaCl; 2. Sepharose Q Fast Flow).

The kinetic parameters of the laccase were determined on ABTS, syringaldazine (4-hydroxy3,5-dimethoxybenzaldehyde azine) and DMP (2,6dimethoxyphenol) as substrates in $0.1 \mathrm{M}$ acetate buffer $\mathrm{pH} 5.0$ at $50^{\circ} \mathrm{C}$ as described above. The effects of some compounds such as $\mathrm{NaCl}, \mathrm{NaBr}$, EDTA, diethyldithiocarbamate (DDC), L-cysteine, thiourea, ethanol and methanol on laccase activity at various concentrations were tested. $\mathrm{IC}_{50}$-values represent the concentration at which $50 \%$ inhibition was found.

\section{Bleaching of cotton}

Cotton fabrics were first washed with a solution of Lutensol ON 30 in deionised water (enough volume to cover the fibre) for $15 \mathrm{~min}$ at boiling temperature followed by washing with tap water to remove the soap. Dried samples of $1 \mathrm{~g}$ were pre-treated with laccase in $0.1 \mathrm{M}, \mathrm{pH}$ 5.0, acetate buffer at different conditions such as enzyme concentration, bath volume, temperature, process duration, agitation level and addition of mediators. The blank and control were done without enzyme and heat-inactivated laccase, respectively, at the same conditions. After the pretreatment, cotton was washed with Lutensol as described above. Bleaching was carried out for $1 \mathrm{~h}$ at $90^{\circ} \mathrm{C}$, with a solution containing (o.w.f.): $3.5 \%$ of silicate $\left(\mathrm{Na}_{2} / \mathrm{SiO}_{2}\right)$, $1 \% \mathrm{Na}_{2} \mathrm{CO}_{3}, 1 \% \mathrm{NaOH}$ and $35 \%$ of $4 \% \mathrm{H}_{2} \mathrm{O}_{2}$. Cotton was washed and dried. The Berger-Whiteness of the fabrics was determined using a Spectraflash machine from Datacolor International (Luzern, Switzerland) with the program DataMatch 3.5, before and after pre-treatment as well as after bleaching. Pre-treatment and bleaching were carried out in triplicate in an Ahiba Spectradye-Datacolor dyeing apparatus (Datacolor International, Luzern, Switzerland), in closed vessels. 
Similarly, cotton flavonoids at a concentration of $0.08 \mathrm{mM}$ were incubated with laccase at $55^{\circ} \mathrm{C}$ within $1 \mathrm{~h}$ and subsequently with $\mathrm{H}_{2} \mathrm{O}_{2}$ for another hour at $90^{\circ} \mathrm{C}$.

Oxygen consumption was measured with an inoLab Oxi Level 2, with a sensor CellOx 325 from WTW. The fabric $(1 \mathrm{~g})$ was pre-treated in a closed vessel (OxiCal-P from WTW) with $50 \mathrm{ml}$ acetate buffer, $\mathrm{pH} 5.0$, until the temperature of $50^{\circ} \mathrm{C}$ was achieved. At stable temperature $\left(50^{\circ} \mathrm{C}\right)$, laccase was injected and the reaction was carried out for $1 \mathrm{~h}$.

\section{Results and discussion}

Isolation of fungi oxidizing cotton flavonoids

Sixteen fungal strains were isolated from decayed plant material. When incubated on agar plates containing flavonoids from cotton and other sources, darkening zones of about $1 \mathrm{~cm}$ around growth zones of three fungi identified as Rhizopus oryzae, Trametes versicolor and Trametes hirsuta indicated secretion of extracellular enzymes oxidizing these flavonoids. The new isolate of T. hirsuta (BT2566) showed the most pronounced effect of darkening and was thus selected for further studies. When T. hirsuta was cultivated on agar plates containing different cotton flavonoids, an increase of the growth rate (colony diameter) as compared to a control of $1.5 \mathrm{~cm}$ corresponding to $16.7 \%$ in case of morin, luteolin and rutin was observed. This is in agreement with previous observations that flavonoids present in cotton can enhance growth of microorganisms (Becard et al. 1992; Ardon et al. 1996). Based on spectroscopic investigations extracellular enzymes of Trametes hirsuta were able to oxidise the flavonoids morin, luteolin (Fig. 2), quercetin and rutin while apigenin was not attacked. Interestingly, oxidation of flavonoids correlated with the activity of laccase in the culture of T. hirsuta. To confirm that laccase activity could be responsible for oxidation of flavonoids this enzyme was purified.

\section{Enzyme purification and characterisation}

According to activity staining of SDS-gels T. hirsuta produced two laccases with molecular masses of 60.7 and $51.0 \mathrm{kDa}$. The $60.7 \mathrm{kDa}$ laccase was purified in four steps by fractionated ammonium sulphate precipitation and chromatography. A yield of $43 \%$ laccase activity was achieved,
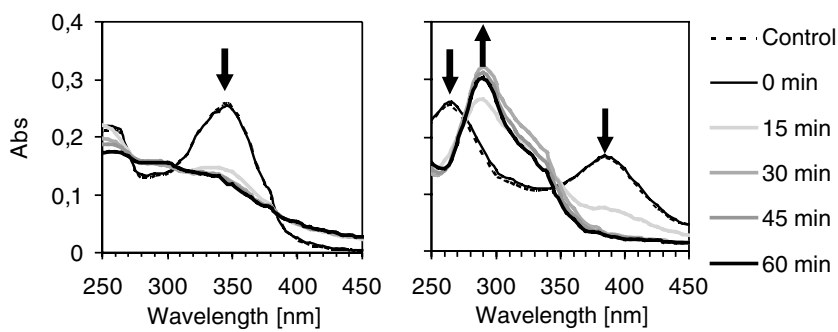

Fig. 2 Oxidation of luteolin and morin with extracellular enzymes from $T$. hirsuta
Table 1 Specificity of the $60.7 \mathrm{kDa}$ laccase from Trametes hirsuta on different substrates

\begin{tabular}{lll}
\hline Substrate & $K_{\mathrm{m}}[\mu \mathrm{M}]$ & $k_{\mathrm{cat}}\left(\mathrm{s}^{-1}\right)$ \\
\hline ABTS & 75.5 & 72.5 \\
Syringaldazide & 20.9 & 96.3 \\
DMP & 49.4 & 32.7 \\
Quercitin & 7.8 & 0.91 \\
Rutin & 5.0 & 0.28 \\
Morin & 5.5 & 0.09 \\
Luteolin & 11 & 0.59 \\
\hline
\end{tabular}

which is acceptable since only one of the two laccases accounting for the initial laccase activity were isolated in this procedure. The molecular mass of the purified laccase obtained with SDS-PAGE (60.7) was confirmed with MALDI-TOF peptide mass mapping experiments which revealed that the purified protein showed sequence homology with lignolytic phenol oxidases from $T$. versicolor (Sequence coverage:14\%, estimated $Z$ score:1.14). In agreement with general characteristics reported for laccases from other fungi both activity and stability optima of the $60.7 \mathrm{kDa}$ laccase from $T$. hirsuta BT2566 were in the acid $\mathrm{pH}$ range between 3 and 4 .

DDC, L-cysteine and thiourea were strong inhibitors for the 60.7 laccase from $T$. hirsuta $\mathrm{BT} 2566$ with $\mathrm{IC}_{50}$ values of $1.5,0.1$ and $1 \mathrm{mM}$ which is in agreement with the results for a $45 \mathrm{kDa}$ laccase from a different strain of $T$. hirsuta. (Abadulla et al. 2000). Compared to this laccase, the 60.7 laccase from T. hirsuta BT2566 was more sensitive against $\mathrm{NaBr}$ and EDTA $\mathrm{IC}_{50}$ values $100 \mathrm{mM} \mathrm{NaBr}$ and $50 \mathrm{mM}$ EDTA compared to $190 \mathrm{mM} \mathrm{NaBr}$ and $200 \mathrm{mM}$ EDTA, respectively.

The $60.7 \mathrm{kDa}$ laccase from $T$. hirsuta was able to oxidise various flavonoids from cotton and other sources (Table 1). There is no information in the literature about laccasecatalysed oxidation of flavonoids from cotton. However, browning of foods due to oxidation of flavonols (quercetin, morin and rutin) with mushroom polyphenoloxidase and horseradish peroxidase has been studied. For both enzymes the same reaction products were detected indicating similar reaction mechanisms. In the case of quercetin, comparison of our spectra (isosbestic points) with these literature data suggests formation of o-quinones (Makris and Rossiter 2002).

In agreement with our negative results for apigenin, the presence of the 3-hydroxyl group in flavonoids was found to be essential for enzymatic oxidation to occur. Similarly, a laccase from Polyporus versicolor required substituents at the C-3 position and a phenyl group at the $\mathrm{C}-2$ position (Pickard and Westlake 1970). On the other hand, we found reasonable oxidation of luteolin which does not contain a hydroxy group in the $\mathrm{C} 3$ position. However, in contrast to apigenin, luteolin has a 2-catechol function on the B ring. Interestingly, with the same number of hydroxyl substituents on the B ring, the substitution pattern seems to determine different reaction pathways (Makris and Rossiter 2002). Our results obtained with rutin indicate that glycosylation in the $\mathrm{C} 3$ position might negatively 
influence enzymatic oxidation when compared to the aglycon (quercetin). Similarly, lower oxidation rates were measured with a laccase from Polyporus versicolor for flavonols glycosylated at the C-3 position (Pickard and Westlake 1970) and for polyphenol oxidase and horseradish peroxidase (Makris and Rossiter 2002).

Oxidative polymerisation of rutin oxidation has previously been described for a Myceliophthora laccase and antioxidant properties of the resulting polymer were proven (Kurisawa et al. 2003). There is only little known about mechanistic aspects of enzymatic oxidation of flavonoids. Although some authors have reported cleavage of the flavonoid skeleton no smaller molecules were detected during oxidation of quercetin, morin and rutin with mushroom polyphenol oxidase and horseradish peroxidase (Makris and Rossiter 2002). Similarly, oxidation of quercetin and rutin by horseradish or soybean peroxidase lead to polymerisation products (Mejias et al. 2002). As reported for many laccases, syringaldazide was a good substrate in terms of catalytic efficiency for the T. hirsuta (Table 1) laccase followed by ABTS and DMP.

Incubation of the laccase with cotton resulted in appearance of brown colour most likely due to oxidation of flavonoids. This colour change of flavonoids upon enzymatic oxidation has been described for many flavonoids and is of major concern in the storage of food (Makris and Rossiter 2002). However, even though the laccase treatment alone thus resulted in a decrease of the cotton whiteness, significant whiteness improvements of $8.5 \%$ were obtained after subsequent hydrogen peroxide bleaching compared to non-enzyme-pre-treated controls (Fig. 3). However, the effect strongly depended on the treatment conditions such as agitation and bath volume. Laccase pre-treatment can either lead to a higher whiteness of fabrics or to savings in hydrogen peroxide consumption. This improvement can be of significant importance for the further steps of cotton preparation such as dyeing or fibre finishing and coating, increasing the water wettability of cotton, the adsorption ability and accessibility of components of the fibre finishing such as dyes or surfactants.

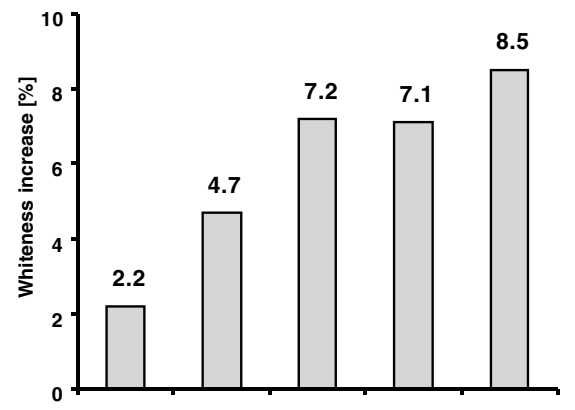

\begin{tabular}{|l|c|c|c|c|c|}
\hline Agitation level (r.p.m.) & 40 & 70 & 70 & 70 & 70 \\
\hline Laccase activity (nkat g-1) & 60 & 60 & 380 & 380 & 380 \\
\hline Bath volume (mL) & 40 & 40 & 40 & 60 & 80 \\
\hline
\end{tabular}

Fig. 3 Cotton whiteness improvement after pre-treatment with the $60.7 \mathrm{kDa}$ laccase from Trametes hirsuta for $1 \mathrm{~h}$ at $50^{\circ} \mathrm{C}$ and different incubation conditions
The mechanism of this whiteness improvement seems to be much more complex than enzymatic in-vitro oxidation of individual flavonoids. Nevertheless, laccase activity dependent oxygen consumption in the presence of cotton clearly indicated oxidation of flavonoids (data not shown). Oxidized flavonoids in cotton (e.g. o-quinones from odiphenols) could potentially react with each other resulting in brown or black polymers or with other phenolics (residual lignin) contained in cotton. Obviously this oxidation by laccase renders the flavonoids more soluble or susceptible to subsequent peroxide bleaching.

\section{Conclusion}

In summary we have shown for the first time that a laccase from a newly isolated strain of T. hirsuta was responsible for whiteness improvement of cotton most likely due to oxidation of flavonoids. Replacement of hydrogen peroxide for bleaching by an enzymatic bleaching system would not only lead to better product quality due to less fibre damage but also to substantial savings of washing water needed for removal of peroxide. Future investigation should focus on both mechanistic aspects on enzymatic bleaching of cotton by e.g. assessing the potential of other oxidases.

Acknowledgements This study was supported by the European Project OXITEX

\section{References}

Abadulla E, Tzanov T, Costa S, Robra KH, Cavaco-Paulo A, Gübitz GM (2000) Decolorisation and detoxification of textile dyes with a laccase from Trametes hirsuta. Appl Environ Microbiol 66:3357-3362

Almansa E, Kandelbauer A, Pereira L, Cavaco-Paulo A, Gübitz GM (2004) Influence of structure on dye degradation with laccase mediator systems. Biocatal Biotransform 22:315-324

Ardon O, Kerem Z, Hadar Y (1996) Enhancement of laccase activity in liquid cultures of the ligninolytic fungus Pleurotus ostreatus by cotton stalk extract. J Biotechnol 51:201-207

Becard G, Douds DD, Pfeffer P (1992) Extensive in vitro hyphal growth of vesicular-arbuscular mycorrhizal fungi in the presence of carbon dioxide and flavonols. Appl Environ Microbiol 58:821-825

Hedin PA, Jenkis JN, Parrot WL (1992) Evaluation of flavonoids in Gossypium arboretum (L.) cottons as potential source of resistance to Tobacco, Budworm. J Chem Ecol 18

Kandelbauer A, Guebitz GM (2005) Bioremediation for the decolorisation of textile dyes, a review. In: Lichtfouse E, Schwarzbauer J, Robert D (eds) Environmental chemistry. Springer-Verlag, Heidelberg, pp 269-288

Kurisawa M, Chung Joo E, Uyama H, Kobayashi S (2003) Enzymatic synthesis and antioxidant properties of poly(rutin). Biomacromolecules 4:1394-1399

Makris DP, Rossiter JT (2002) An investigation on structural aspects influencing product formation in enzymic and chemical oxidation of quercetin and related flavonols. Food Chem 77:177-185

Mejias L, Reihmann MH, Sepulveda-Boza S, Ritter H (2002) New polymers from natural phenols using horseradish or soybean peroxidase. Macromol Biosci 21:24-32

Pickard MA, Westlake DWS (1970) Fungal metabolism of flavonoids. Purification, properties, and substrate specificity of an inducible laccase from Polyporus versicolor PRL 572. Can J Microbiol 48:1351-1358 